\title{
BRUXISMO EM ODONTOPEDIATRIA
}

Marco Aurelio Ferreira LUIZ, Thiago Ferreira LUIZ, Maria Gisette Arias PROVENZANO, Karine TAKAHASHI, Marina Lurdes FRACASSO

Este trabalho tem como objetivo fazer uma revisão de literatura sobre a etiologia e as condutas clínicas mais adequadas para realizar diagnóstico e tratamento de crianças com bruxismo. Este hábito tem gerado uma grande preocupação, pois atualmente tem se mostrado cada vez mais presente entre as crianças e repercute de forma significativa no sistema estomatognático quando de forma intensa e prolongada. O bruxismo é considerado uma parafunção, com ranger dos dentes durante movimentos não funcionais do sistema mastigatório, que ocorre tanto durante o dia como a noite. Como conseqüência o bruxismo pode resultar em abrasão dos dentes decíduos e permanentes, podendo causar alterações na dimensão cervico incisal ou oclusal. Pôde-se concluir que este hábito está muito presente no público infantil e sua etiologia é multifatorial no qual o fator psicológico é preponderante, talvez pela presença do medo, tensões e ansiedade entre as crianças. Desta forma, como este hábito é complexo, o tratamento ideal é uma terapia multidisciplinar entre dentistas, psicólogos, médicos para alcançar resultados mais eficientes. Palavras Chaves: Bruxismo; Crianças; Desgaste Dentário. 